\title{
The NHS in 2017
}

\author{
Fiona Godlee editor in chief
}

The BMJ

In 2008, when the NHS turned 60, a BMJ series concluded, "The most thoughtful birthday present the NHS could receive would be an extended period of calm before the next round of reforms is unleashed" (doi:10.1136/bmj.a524). Sadly, this isn't what happened. Instead, as Sarah Wollaston, chair of the UK parliament's health select committee, writes this week, the incoming coalition government imposed a disruptive, demoralising, and distracting reorganisation at a time of economic crisis and rapidly rising demand (doi:10.1136/bmj. j5). Rather than integrating health and social care, the 2012 Health and Social Care Act bred even more fragmentation in England.

Scotland and Wales took a different path, abolishing the split between purchasers and providers to aid integration. In England the NHS Five Year Forward View promised a shift from competition to more integrated commissioning and a focus on prevention. But rather than funding this properly the government has engaged in a dispiriting spat over how much additional money has been provided. Wollaston is clear that the actual figure- $£ 4.5 \mathrm{bn}$ ( $€ 5.3 \mathrm{bn}$; $\$ 5.5 \mathrm{bn}$ ) over five years—represents a fall in real term spending per person, made acutely worse by cuts in social care and public health.

At this critical moment in the NHS's history a new BMJ series launched this week looks at the forces shaping the health service and the prospects for a sustainable future (doi:10.1136/bmj. i6691). The first main article considers the effect of societal change on the NHS (doi:10.1136/bmj.i6738). An ageing population, worsening social determinants of health, greater public expectations, the high cost of new treatments, and the damage to public health from air pollution and climate change all contribute to the growing demand for healthcare. Can the NHS survive under these societal pressures, so different from the circumstances in which it was founded? Can it deliver on its founding principles: to provide universal, equitable, comprehensive, and high quality healthcare free at the point of need?

Further articles in the series will look at the effects of government policy, including service reform, funding, and regulation, and whether the role of clinicians has evolved sufficiently to cope with the demands of the modern day health service.

As for Wollaston, she is scathing about the "dismal" political response: the failure to grasp the scale of the financial challenge facing health and social care, and the damaging consequences of their continuing separation. Her advice? Visit your MP and invite them to your workplace. "We need as many MPs as possible to understand the urgency that they work together to find a sustainable long term settlement and the consequences for their constituents of political failure." 